\title{
CULTIVO ORGÂNICO DE CEBOLINHA (Allium fistulosum L.) SOB DIFERENTES MANEJOS DE COBERTURA DE SOLO.
}

\author{
Carla Almeida de Souza ${ }^{1}$; Felipe Oliveira Nunes ${ }^{2}$; Gleidane de Freitas Souza $^{3}$ e Marina \\ Siqueira Castro ${ }^{4}$ \\ 1. Bolsista PROBIC-UEFS, Graduanda em Agronomia, Universidade Estadual de Feira de Santana, Membro do Nea-Trilhas \\ -Núcleo de Estudos em Agroecologia e-mail: carlalmeidaagronomia@hotmail.com \\ 2. Pesquisador/colaborador do NEA-Trilhas, Biólogo e mestre em Ciências Ambientais pela Universidade Estadual de Feira \\ de Santana, e-mail: nunesfo@ gmail.com \\ 3. Membro do NEA-Trilhas e graduanda em Agronomia na Universidade Estadual de Feira de Santana, \\ e-mail: gleidane@liive.com \\ 4. Orientadora/Coordenadora do Centro de Agroecologia- Cearis e do NEA-Trilhas, Departamento de Ciências Biológicas, \\ Universidade Estadual de Feira de Santana, e-mail: marinacastro@uefs.br
}

PALAVRAS-CHAVE: matéria orgânica; cobertura vegetal; manejo de solo.

\section{INTRODUÇÃO}

A produção da agricultura orgânica cresce acentuadamente ao decorrer dos anos, devido a grande demanda alimentícia, e a busca de alimentos mais saudáveis e livres de agrotóxico, ou seja, agroecológicos, fazendo com que a horticultura nacional atinja grandes patamares na exploração comercial, gerando lucro para os produtores. (GLIESSMAN, S. R. 2000. 653p).

A cebolinha (ALLIACEAE, Allium fistulosum) é uma hortaliça muito apreciada pela população e cultivada em quase todos os territórios brasileiros. A cebolinha produzida no Nordeste tem grande consumo no Brasil, sendo comercializada em diversos lugares, como nas feiras locais e regionais, bem como em estabelecimentos comerciais. A região de Amélia Rodrigues-Ba onde está situado o Centro de Agroecologia Rio Seco - Cearis, vive esta realidade, pois é um local rodeado de comunidades que vivem da agricultura familiar, tendo como foco o plantio e comercialização de hortaliças, dentre elas a cebolinha.

Práticas baseadas nos princípios da agroecologia contribuem para a conservação do solo e para a nutrição das plantas cultivadas, fazendo necessário o conhecimento de métodos para preservação desse solo, através do uso de práticas sustentáveis, como a cobertura vegetal.

A cobertura do solo em hortaliças vem sido utilizada para reduzir impactos no mesmo, como: a compactação; baixo teor de matéria orgânica e incidência de plantas daninhas, ajudando na contribuição de manutenção da temperatura e umidade do solo, o que gera níveis propícios para o desenvolvimento das plantas (MULLER, 1991).

Neste trabalho, objetivou-se estudar diferentes manejos de cobertura do solo no cultivo de cebolinha (cobertura morta utilizando palhada e a cobertura viva consorciando a cebolinha com a Crotalaria - FABACEAE Crotalária juncea cv.), avaliando os parâmetros agronômicos da cultura através de observações de campo e análise de dados por testes estatísticos. Diversos indícios demonstram que práticas sustentáveis, principalmente no manejo do solo, que beneficiem na produtividade das hortaliças, acabam sendo de extrema relevância para os agricultores familiares que residem nas comunidades vizinhas ao Cearis, haja vista que estes tem por atividade agrícola principal, o cultivo de hortaliças e muitos desejam adotar sistemas de base agroecológica.

\section{MATERIAL E MÉTODOS}

O experimento foi desenvolvido no Centro de Agroecologia Rio Seco - Cearis (antiga Estação Experimental da Empresa Baiana de Desenvolvimento Agrícola - EBDA), recentemente cedido à Universidade Estadual de Feira de Santana - UEFS, localizado às 
margens da rodovia Salvador - Feira de Santana, BR 324, no município de Amélia Rodrigues, Bahia.

Neste experimento, foram estudados diferentes manejos de cobertura do solo, sendo eles: cobertura morta utilizando palhada e cobertura viva consorciando a cebolinha com a leguminosa crotalaria.

O delineamento experimental adotado foi em blocos casualizados, com parcelas subdivididas e quatro repetições (ZIMMERMANN,2014). O plantio das hortaliças foi realizado em quatro diferentes blocos (canteiros modelo "buraco fechadura"), feitos manualmente, com uma profundidade de 30 a $40 \mathrm{~cm}$ de solo. A largura utilizada foi de cerca de 1 metro, o que facilitou o manejo da cultura e a circunferência do canteiro proporcionou cerca de 9 metros lineares de leira, diminuindo o espaço utilizado para implantação do experimento.

Cada canteiro (bloco) foi composto por três tratamentos, sendo o tratamento 1 cobertura morta (cebolinha + palhada), tratamento 2 cobertura viva (cebolinha + crotalaria) e o tratamento 3 controle (apenas cebolinha). A condução dos tratamentos nos blocos foi realizada da seguinte forma: no tratamento 1, o cultivo da cebolinha foi associado a prática agroecológica da cobertura morta que consiste em utilizar restos vegetais sobre o solo, buscando diminuir a perda da umidade, proporcionar uma maior retenção de água e incorporar matéria orgânica ao solo; no tratamento 2 , o cultivo da hortaliça foi associado a prática da cobertura viva, que mantêm no solo toda vegetação presente quer seja cultivada, ou espontânea, com a finalidade de serem incorporadas ao solo para preservar a sua fertilidade, visando proporcionar uma maior disponibilidade de macro e micronutrientes.(CASTRO et al., 2004); e no tratamento 3 o controle, não houve nenhuma prática agroecológica em sua condução, a cebolinha foi plantada em solo descoberto. Os efeitos da atuação das diferentes coberturas vegetais na cebolinha foram avaliados através dos seguintes parâmetros: altura do perfilho, diâmetro do bulbo, matéria natural (fresca) e matéria seca.

O programa estatístico escolhido para a análise de dados do experimento foi o Past, por obter boa eficácia nas analises, ser de fácil acesso e ter grande uso na área de pesquisas agronômicas (HAMMER et al.2001).

\section{RESULTADOS E DISCUSSÃO}

A cobertura morta (palhada), com base na análise dos dados, obteve um melhor desenvolvimento da cebolinha em relação a altura do perfilho e também ao diâmetro do bulbo, possuindo as maiores medias; seguido pelo controle e por fim, o tratamento com a cobertura viva obteve as menores médias. Este melhor desenvolvimento com a cobertura morta, tem como base diversos princípios ecológicos, dentre eles a diminuição no surgimento de plantas espontâneas, estabilidade na temperatura do solo, retenção de água e aumento de biomassa. (DAROLT, 2002; MATEUS et al, 2004). O principal fator é a maior concentração de matéria orgânica no solo, melhorando a sua estrutura e adsorção de água. (PRIMAVESI, 2002).

A matéria natural obteve melhor resultado pelo teste de médias com o tratamento controle, seguido da cobertura morta e por fim a cobertura viva. $\mathrm{O}$ tratamento com cobertura viva não obteve grandes resultados do ponto de vista agronômico, isso se da devido a competição por água, luz e nutrientes resultando em uma menor massa fresca, menor diâmetro de bulbo, altura do perfilho e massa seca (ERASMO et al, 2004). Já na massa seca o tratamento com cobertura morta (palhada) se destacou tendo um aumento considerável. Este efeito também foi observado em alface por (SANTOS et al, 2001), que verificou melhoria nas características do solo, sendo a incorporação de palhada mais produtiva que os demais tratamentos, o que propicia melhor efeito residual, observado nos dados de massa seca. 
Apesar dos dados estatísticos Anova para blocos casualizados demonstrarem que os tratamentos não tiveram diferença significativa entre si, há uma tendência que indica que o Tratamento 1 com cobertura morta (palhada) foi mais eficaz no desenvolvimento da altura do perfilho, diâmetro do bulbo e matéria seca, diferindo apenas da matéria natural que obteve melhor resultado no tratamento 3 (controle) através dos testes de média e desvio padrão (tabela 1).

Tabela 1. Altura média do perfilho $(\mathrm{cm})$, Diâmetro do bulbo $(\mathrm{mm})$, Massa seca e massa natural (kg), aos 90 dias, de acordo os tratamentos. Centro de Agroecologia Rio Seco/UEFS - Amélia Rodrigues-Ba. 2017.

Média \pm Desvio Padrão

\begin{tabular}{ccccc}
\cline { 2 - 5 } Tratamentos & Altura & Diâmetro do bulbo & MS & MN \\
\hline T1 & $29,26 \pm 6,33$ & $10,26 \pm 1,54$ & $0,10 \pm 0,04$ & $0,94 \pm 0,43$ \\
T2 & $20,79 \pm 4,85$ & $8,2 \pm 1,82$ & $0,05 \pm 0,03$ & $0,59 \pm 0,38$ \\
T3 & $26,86 \pm 4,51$ & $9,69 \pm 2,25$ & $0,09 \pm 0,04$ & $1,15 \pm 0,59$ \\
\hline
\end{tabular}

Legenda: Pela prova da Two-way ANOVA withoutreplication, podemos afirmar que o Trat 1 apresentou melhor média, porém, não obteve diferença significativa dos demais tratamentos. $\mathrm{O}$ trat 2 apresentou pior media e o trat 3 foi intermediário. $(\mathrm{p}<0,05)$.

Portanto, pode-se inferir que a cobertura morta é uma prática de manejo de solo de importância significativa na cultura da cebolinha e de outras hortaliças, contribuindo para otimização no uso de recursos hídricos, manutenção da umidade e temperatura adequadas no solo e beneficiando a manutenção da vida no mesmo. Também pode-se indicar que o plantio da crotalaria para adubação verde deve ser realizado antes do plantio da cultura principal, evitando assim a competição pelos nutrientes do solo, água e luminosidade. Destaca-se também, a eficiência do canteiro modelo "buraco fechadura", haja vista a facilidade no manejo dos cultivos e redução do espaço utilizado para produção, importante quesito para a agricultura familiar cujas propriedades normalmente são de pequeno tamanho.

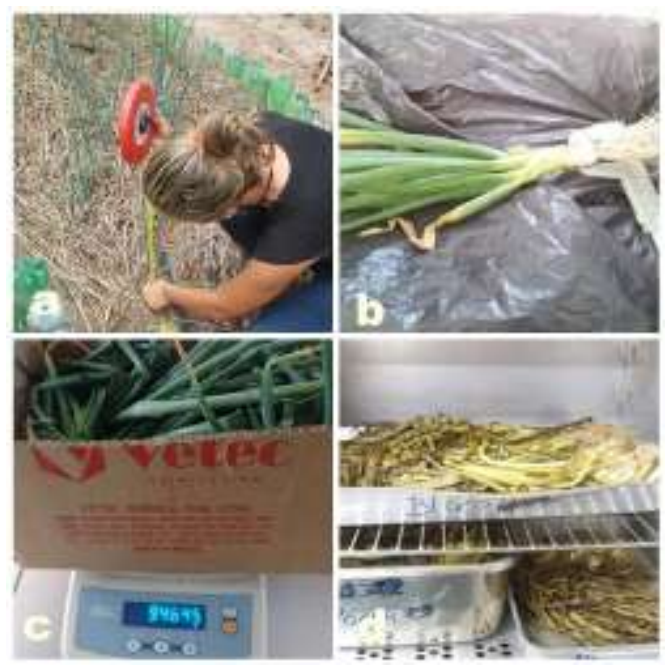

Legenda: Medição da altura do perfilho da cebolinha (Alliumfistulosum) A

- Medição do diâmetro do bulbo; B

- Pesagem da matéria natural. C

- Processo de secagem da matéria seca. D.

Fotos: Carla Almeida 


\section{REFERÊNCIAS}

CASTRO, C.M. et al. Adubação verde como fonte de nitrogênio para a cultura da berinjela em sistema orgânico. Pesquisa AgropecuáriaBrasileira, Brasília, v.39, n.8, p.779785.2004.

Disponível em:<http://www.scielo.br/scielo.php?script=sci_arttext\&pid=S0100204X2004000800008\&ln $\mathrm{g}=\mathrm{en} \& \mathrm{nrm}=\mathrm{iso} \& \operatorname{tn} \mathrm{g}=\mathrm{pt}>$.

DAROLT, M.R. Agricultura orgânica: inventando o futuro. Londrina: IAPAR, 2002. 250p.

ERASMO, E.A.L. et al. Potencial de espécies utilizadas como adubo verde no manejo integrado de plantas daninhas. PlantaDaninha, Viçosa, v.22, n.3, p.337-342, 2004. Disponível em: $<\mathrm{http}: / / \mathrm{www}$. scielo.br/scielo.php?script=sci_arttext\&pid=S0100$83582004000300002 \& \operatorname{lng}=$ pt\&nrm=iso\&tlng=pt $>$.

GLIESSMAN, S. R. Agroecologia: processos ecológicos em agricultura sustentável. Porto alegre: Ed. Universidade/UFRGS, 2000. 653p

HAMMER, Ø., Harper, D.A.T. \& Ryan, P.D., 2001. PAST: Paleontological statistics software package for education and data analysis. PalaeontologiaElectronica 4(1): 9p. Disponível em: http://palaeo-electronica.org/2001_1/past/issue1_01.htm

MATEUS, G.P. et al. Palhada do sorgo de guiné gigante no estabelecimento de plantas daninhas em área de plantio direto. Pesquisa AgropecuáriaBrasileira, Brasília, v.39, n.6, p.539-542, 2004. Disponível em:<http://www.scielo.br/scielo.php?script=sci_arttext\&pid=S0100204X2004000600004\&ln $\mathrm{g}=\mathrm{en} \& \mathrm{nrm}=\mathrm{iso} \& \mathrm{t} \operatorname{lng} \mathrm{g}=\mathrm{pt}$

MULLER, A. G. Comportamento térmico do solo e do ar em alface (Lactuca sativa L.) para diferentes tipos de cobertura do solo. 1991. 77 f. Dissertação (Mestrado) - Escola Superior de Agricultura Luiz de Queiroz, Piracicaba, 1991.

PRIMAVESI, A. O manejo ecológico do solo: agricultura em regiões tropicais. São Paulo: Nobel, 2002. 541p.

SANTOS, R.H.S. et al. Efeito residual da adubação com composto orgânico sobre o crescimento e produção de alface.Pesquisa Agropecuária Brasileira, Brasília, v.36, n.11, p.1395-1398, 2001. Disponível em: <http://www.scielo.br/s c i e lo . p h p ? s c r i p t = s c i a r t t e x t \& p i d = S 0100 -204X2001001100010\&lng=en\&nrm=iso\&tlng=pt>.

ZIMMERMANN, F.J.P. Estatistica aplicada a empresa agrícola -2.ed.- Brasília, DF: Embrapa, 2014 